\title{
Traqueobroncopatía osteocondroplástica en un paciente con diagnóstico reciente de infección por el virus de la inmunodeficiencia humana
}

\author{
Tracheobronchopathia osteochondroplastica in a patient \\ with a recent HIV infection
}

Liliana Fernández T., MD.(1); Alejandro González, MD.(2); Sebastián Calle, MD. ${ }^{(3)}$; LUZ F. SUA, MD., PHD. ${ }^{(4)}$

\begin{abstract}
Resumen
La traqueobroncopatía osteocondroplástica es una condición rara de causa desconocida, caracterizada por la presencia de nódulos calcificados que se proyectan dentro del lumen del árbol traqueobronquial; es además, una causa de tos crónica. El diagnóstico se hace documentando las lesiones típicas en la broncoscopia. Es una enfermedad benigna que usualmente no requiere un tratamiento específico, pero en algunos casos puede causar obstrucción de la vía aérea que requiere tratamiento con resección endoscópica o quirúrgica. Se reporta el caso de un paciente con un diagnóstico reciente de infección por el virus de la inmunodeficiencia humana en quien se encontraron lesiones típicas de traqueobroncopatía osteocondroplástica durante el estudio de los síntomas respiratorios.
\end{abstract}

Palabras clave: traqueobroncopatía osteocondroplástica, broncoscopia.

\begin{abstract}
Osteochondroplastic tracheobronchopathy is a rare condition of unknown cause. It is characterized by the presence of calcified nodules that project into the lumen of the trachobronchial tree; it is also a cause of chronic cough. Diagnosis is made by documenting its typical lesions via bronchoscopy. It is a benign condition that does not usually require specific treatment; however, in some cases it may cause obstruction of the airway, requiring endoscopic or surgical ablation. We report the case of a patient recently diagnosed with human immunodeficiency virus infection in whom the lesions typical of osteochonroplastic tracheobronchopathy were found during the investigation of respiratory symptoms.
\end{abstract}

Keywords: osteochondroplastic tracheobronchopathy, bronchoscopy.

\section{Introducción}

La traqueobroncopatía osteocondroplástica es una condición benigna poco común, de causa desconocida, caracterizada por la presencia de lesiones calcificadas sobre los arcos cartilaginosos del árbol traqueobronquial, que se proyectan a la luz, causando un grado variable de obstrucción, respetando la pared membranosa posterior. Los síntomas más frecuentes de la son tos crónica y sibilancias; el diagnóstico se considera al encontrar las lesiones características en la broncoscopia.

Tiene un curso indolente, no requiere tratamiento específico, pero en algunos casos puede provocar obstrucción de la vía aérea y requerir manejo con resección endoscópica o quirúrgica. Se reporta el caso de un paciente

\footnotetext{
(1)Medicina Interna, Neumología, Neumología Intervencionista. Fundación Valle del Lili, Profesora Clínica Asociada, Facultad de Ciencias de la Salud, Universidad ICESI, Cali-Colombia.

${ }^{(2)}$ Médico internista. Facultad de Medicina, Universidad ICESI, Cali-Colombia. 3Estudiante de Medicina, Facultad de Medicina, Universidad ICESI, Cali-Colombia.

4Anatomía Patológica y Patología Clínica, Patología Pulmonar, Ciencias Biomédicas, Fundación Valle del Lili, Profesora Clínica Asistente, Facultad de Ciencias de la Salud, Universidad ICESI, Cali-Colombia Correspondencia: Liliana Fernández Trujillo, correo electrónico: 1fernandez@fcvl. org.

Recibido: 26/10/14. Aceptado 10/12/14.
} 
con diagnóstico reciente de virus de la inmunodeficiencia humana (VIH) en quien en el estudio de síntomas respiratorios, se documentaron lesiones típicas de traqueobroncopatía osteocondroplástica que se confirmaron con el estudio histológico de las mismas.

\section{Caso}

Paciente de sexo masculino, de 61 años de edad, proveniente de zona rural, sin antecedentes patológicos de importancia, no fumador, quien consultó con un cuadro clínico de ocho meses de evolución consistente en tos con expectoración hemoptóica, diaforesis nocturna, fiebre de bajo grado, diarrea y pérdida de peso, además con antecedente epidemiológico importante de contacto estrecho con una familiar que falleció por tuberculosis multidrogorresistente. En el examen de ingreso se encontraron signos vitales normales, en la fosa supraclavicular derecha una adenomegalia no dolorosa de consistencia firme, murmullo vesicular sin ruidos sobreagregados, corazón sin soplos, abdomen sin masas ni visceromegalias, extremidades sin edema y examen neurológico normal. En los exámenes de laboratorio tenía hemograma con leucopenia, sin anemia o trombocitopenia, proteína $\mathrm{C}$ reactiva de $0,2 \mathrm{mg} / \mathrm{dl}$, pruebas para hepatitis virales negativas, VDRL y RPR no reactivas, prueba de ELISA y Western Blot confirmatorio, positivos para infección por VIH con un conteo de células CD4 en 267 (15\%) y prueba de tuberculina PPD de $10 \mathrm{~mm}$. Se realizó biopsia de la adenomegalia supraclavicular derecha y estudios endoscópicos gastrointestinales que reportaron en los estudios histológicos cambios inflamatorios inespecíficos.

Se realizó una tomografía de tórax que mostró adenomegalias paratraqueales derechas y en ambos hilios pulmonares con áreas calcificadas, sin lesiones parenquimatosas pulmonares ni pleurales. Se llevó a fibrobroncoscopia en donde se observaron lesiones mamelonadas difusas de consistencia dura recubiertas por mucosa de aspecto normal, que se extendían desde la tráquea proximal hasta los bronquios fuentes, y estaban ubicadas sobre los arcos cartilaginosos respeto a la pared posterior membranosa (figura 1). Se tomaron muestras de éstas y se realizó lavado broncoalveolar, para estudio microbiológico y citológico.

En vista de hallazgos se decidió realizar una tomografía tridimensional con reconstrucción de la vía aérea para el estudio de las lesiones (figura 1), donde se observaron mejor las irregularidades en las paredes de la tráquea y los bronquios fuentes, con múltiples lesiones la mayoría calcificadas, que protruían a la luz de la vía aérea, las de mayor tamaño ubicadas a la altura del manubrio esternal sin producir una estenosis significativa de la luz de la vía aérea (figura 1).

Las tinciones y los cultivos del lavado broncoalveolar fueron negativos para bacterias, hongos y Micobacterium tuberculosis, pero se aisló Micobacterium gordonae, que se consideró un germen no patógeno dada las condiciones clínicas y el conteo de células CD4 del paciente.

Se decidió iniciar manejo con terapia antirretroviral que incluyó abacavir, lamivudina y efavirenz y se inició isoniacida durante nueve meses para el manejo de la tuberculosis latente. El paciente continúa



Figura 1. Aspecto escanográfico y broncoscópico de la traqueobroncopatía osteocondroplástica. 
en evaluaciones periódicas ambulatorias, ha tenido buena adherencia al tratamiento farmacológico, ha ganado peso y no ha presentado nuevos episodios de expectoración hemoptoica aunque persiste con tos moderada intermitente.

\section{Discusión}

La traqueobroncopatía osteocondroplástica es una condición benigna poco común de causa desconocida, caracterizada por la presencia de lesiones nodulares sobre los cartílagos de tráquea y bronquios que se proyectan a la luz de la vía aérea, causando obstrucción variable de la misma. Fue descrita por primera vez en 1850 (1) por Wilks et al. como depósitos osificados sobre la laringe tráquea y bronquios. Se han postulado varias teorías acerca de su patogénesis, una es la de Virchow (2), quien sugiere que son encondromas que se calcifican llevando a la formación posterior de los nódulos. Por otro lado, Aschoff- Freiburg (3) sugiere que la osificación se inicia en el tejido conectivo; además algunos investigadores describen que la BMP-2 (del inglés bone morphogenetic protein-2) y el TGF-B1 (del inglés transforming growth factor B1) son posibles promotores de la formación de los nódulos submucosos.

La mayoría de los casos ocurre por encima de los 50 años, aunque se han descrito casos en población pediátrica. Pareciera existir una leve predisposición en el sexo masculino (4). La incidencia real es desconocida; muchos de los casos son diagnosticados en autopsias o como hallazgos incidentales en estudios radiológicos o broncoscópicos. Dentro de la literatura médica se han reportado alrededor de 400 casos. Se ha encontrado asociada a otras condiciones como asma, carcinoma mucoepidermoide, acromegalia y polimiositis. Este caso es el primero reportado en la literatura asociada a una infección por VIH. En la serie de casos más grande reportada, se ha aislado Klebsiella ozaenae (5) en $20 \%$ de los pacientes, germen responsable de la ozena, pero la relación con la traqueobroncopatía osteocondroplástica aún no es clara.

El curso de esta entidad es indolente. Sin embargo, cuando los pacientes se tornan sintomáticos, es variable; presentan disnea, estridor y hemoptisis, esta última usualmente secundaria a la ulceración de los nódulos; es además una causa de tos crónica, la cual se desencadena por el flujo turbulento en la zona, aumento de la sensibilidad del reflejo tusígeno y anormalidades en el aclaramiento mucociliar (6). Las infecciones respiratorias a repetición son frecuentes.

Dentro de los ayudas diagnósticas, los estudios de imágenes como la radiografía de tórax generalmente son normales aunque se pueden observar imágenes relacionadas con complicaciones como atelectasias, bronquiectasias o neumonías. Los estudios tomográficos pueden mostrar estrechez de la luz de la tráquea con lesiones nodulares que pueden estar o no calcificadas, aunque en estadios tempranos o leves también pueden ser normales (7). Las imágenes de reconstrucción tridimensional de la vía aérea son muy útiles en la evaluación e interpretación de los hallazgos, como en el caso expuesto.

La alteración en las pruebas de función pulmonar dependerá del grado de obstrucción; en casos avanzados se observan diferentes grados de obstrucción de la vía aérea central intra o extratorácica (10).

El diagnóstico se hace mediante broncoscopia. Se ha reportado este hallazgo en el $0,4 \%$ de todas las broncoscopias, en tanto que en pacientes en estudio de tos crónica la frecuencia puede alcanzar hasta un $8 \%(8,9)$. Los hallazgos broncoscópicos muestran espículas irregulares de hueso y cartílago que se proyectan hacia la luz del árbol traqueobronquial ubicadas sobre los cartílagos en las paredes anterior y laterales, preservando la pared membranosa en la cual nunca aparecen lesiones. En situaciones en las cuales se encuentren lesiones en la pared membranosa se deben excluir otras causas como la amiloidosis endobronquial y otras entidades que forman parte del diagnóstico diferencial como policondritis, papilomatosis traqueal, enfermedades granulomatosas como la sarcoidosis, la tuberculosis y la granulomatosis con poliangeitis (granulomatosis de Wegener), además de calcificación relacionada con la edad y tumores primarios de la vía aérea y los linfomas de presentación endobronquial. De ahí la importancia de realizar biopsias de las lesiones para contar con confirmación y caracterización histológica. Los segmentos más afectados son los dos tercios distales de 
la tráquea y los bronquios principales; el compromiso laríngeo es raro pero se describe en la literatura.

Las biopsias son difíciles de tomar dadas las características óseas de las lesiones, por lo cual muchos autores consideran que solo es necesaria la visualización endoscópica para el diagnóstico. Los hallazgos histológicos revelan elementos cartilaginosos en la submucosa, metaplasia escamosa epitelial, calcificaciones e inclusive médula hematopoyética en las áreas osificadas, la cual se pudo identificar en este caso (figura 2).

Usualmente tiene buen pronóstico, aunque el trauma traqueal aumenta la tasa de progresión; algunos casos tienen un curso más agresivo que lleva a estenosis traqueal y muerte (11). Puede ser, además, una causa de intubación difícil (12).

No hay un manejo específico definitivo. En caso de síntomas se puede ofrecer manejo con humidificación de la vía aérea, mucolíticos y control de

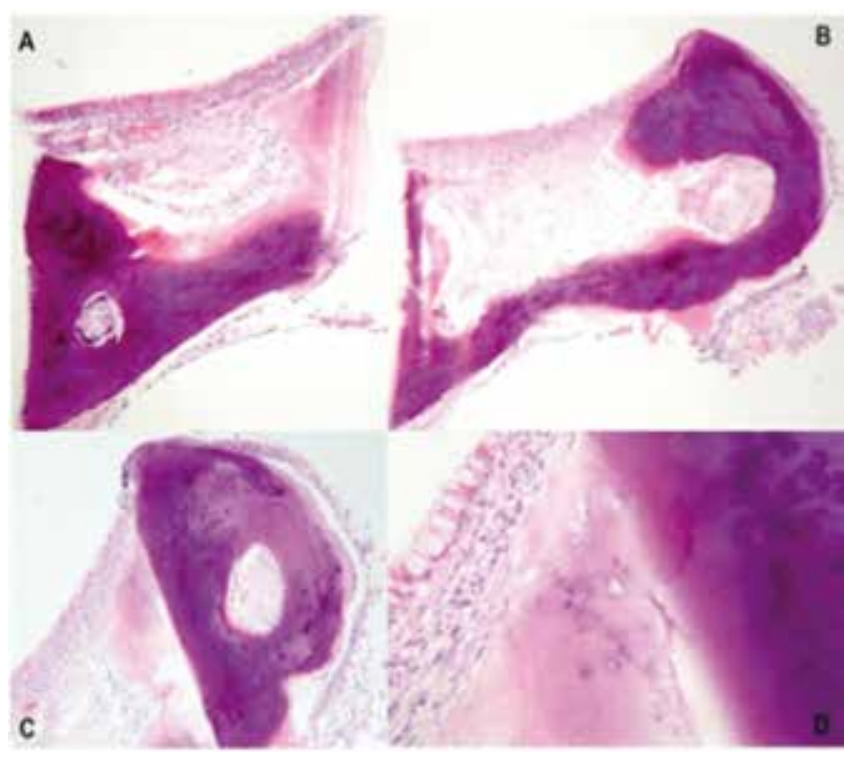

Figura 2. A. B. C. Epitelio respiratorio con nódulos óseos submucosos y formación de tejido hematopoyético; tinción H\&E. D. Epitelio respiratorio ciliado, célula global y área de transición entre tejido óseo y cartilaginoso; tinción H\&E. procesos infecciosos. Los casos severos han sido tratados por vía endoscópica con broncoscopia flexible o rígida, para la remoción de los nódulos con diferentes técnicas como fórceps, láser, electrocoagulación, crioterapia, implante de stent entre otros; adicionalmente, algunos autores describen tratamientos con radioterapia para disminuir la progresión de la enfermedad o procedimientos quirúrgicos que incluyen resección traqueal o traqueostomía (13).

\section{Bibliografía}

1. Wilks S. Ossific deposits on larynx, trachea, and bronchi. Trans Pathol Soc Lond. 1857;8:88.

2. Virchow R. In: Die krankhaften Geschwülste.1st. ed (Vol. 1). Berlin; Hirschwald, 1863. p. 442.

3. Aschoff-Freiburg L. Ueber tracheopathia osteoplastica. Verh Dtsch Gesch Pathol. 1910;14:125-7.

4. Vilkman S, Keistinen T. Tracheobronchopathia osteochondroplastica: report of a young man with severe disease and retrospective review of 18 cases. Respiration. 1995;62:151-4.

5. Leske V, Lazor R, Coetmeur D, Crestani B, Chatté G, Cordier JF. Tracheobronchopathia osteochondroplastica: a study of 41 patients. Medicine. 2001;80:378-90.

6. Chen AY, Donovan DT. Impaired ciliary clearance from tracheopathia osteoplastica of the upper respiratory tract. Otolaryngol Head Neck Surg. 1997;117(6): S102-4.

7. Restrepo S, Pandit M, Villamil MA, Rojas IC, Perez JM, Gascue A. Tracheobronchopathia osteochondroplastica: helical CT findings in 4 cases. J Thorac Imaging. 2004;19:112-6.

8. Sen RP, Walsh TE. Fiberoptic bronchoscopy for refractory cough. Chest. 1991;99:33-5.

9. Decalmer S, Woodcock A, Greaves M, Howe M, Smith J. Airway abnormalities at flexible bronchoscopy in patients with chronic cough. Eur Respir J. 2007;30(6):1138-42.

10. Lundgren R, Stjernberg NL. Tracheobronchopathia osteochondroplastica. A clinical bronchoscopic and spirometric study. Chest. 1981;80:706-9.

11. Molloy AR, McMahon JN. Rapid progression of tracheal stenosis associated with tracheopathia osteo-chondroplastica. Intensive Care Med. 1988;15:60-2.

12. Gurunathan U. Tracheobronchopathia osteochondroplastica: a rare cause of difficult intubation. $\mathrm{Br} \mathrm{J}$ Anaesth. 2010;104(6):787-8. doi: 10.1093/bja/aeq107

13. Tibesar RJ, Edell ES. Tracheopathia osteoplastica: effective long-term management. Otolaryngol Head Neck Surg. 2003;129:303-4. 